\title{
DE BRIEVEN VAN GOUVERNEUR CORNELIS VAN AERSSEN VAN SOMMELSDIJCK AAN DIRECTEUREN DER SOCIETEIT VAN SURINAME UIT HET JAAR 1684
}

\author{
MEDEGEDEELD DOOR
}

MR. R. BIJLSMA

Edele Groot Achtbare Heeren,

Sedert mijne laesten van den 23 Augustij met het schip de St Jan, het welcke verhoope aldaer reets geluckigh ende wel sal sijn gearriveert, sijn hier binnen gecomen schipper Jan Bisschop met sijn schip de Cornelia, nae ouder gewoonte met een hout- en soutbrieff, sulcx ick geresolveert ben hem hier sijn lastgelt te doen betaelen, ende daer inne te continueren tot dat in Zeelandt betere ordre dieswegen werde gestelt ende daerinne werde versien, nevens het schip de Vrede, waer capiteyn op is Pets, comende van Angola met een getal van vierhondert en tien slaven, maeckende een getal van driehondert vijff en vijfftigh peces, volgens sijne aengevens ende die van den supercarga Nicolaes Paravacin tot Angola ingehandelt. Sedert hebben wij besoignes op besoignes gehadt en soo overvloedigh, sijnde de Coert daer immediatelijck opgevolght nevens het vercoopen der slaven ende eijdelijck ende finalijck tot geheel accablement de vuyle ende goddelose trouwloosheijt, ende minedigheijt van den voorz. capiteyn Daniel Petz nevens den supercargo,stuerman, onder stuerman, bootsman, meester ende generalijck van het geheel scheepsvolck, sijnde den voorsz.capiteyn mijn van den beginne seer suspect geweest ende dagelijcx meer en meerder geworden uyt verscheyde voorvallende saecken, waerdoor ick hoe langer hoe meerder wert gepersuardeert ofte geconfirmeert, hetwelcke mijn obligeerde de heer fiscael te ontbieden, hem van mijne suspicie te informeren ende hem te recommanderen van alle vlijdt ende naerstigheyt aen te wenden om hem te betrappen, gelijck ick oock van mijne sijde hetselvige 
soude doen, ende soodanigh is gesuccedeert, dat door alle mijne praecautien, siende geene middelen dat tot haere gewenste eynde soude cunnen geraecken, soo hebben sij haer in de clemme bevindende, raetsaem gevonden haer aen de heer Samuel Nassy te addresseren, van hem versoeckende haer in dese uytterste gelegentheyt goeden raet te willen geven hoe sij haer souden hebben te gedragen. Willem de Bruyn, op wiens plantage het troupje van seven en twintigh slaven was gebracht, niet ophoudende bij den voorsz. capiteyn om van de selvige te werden ontlast, sijnde een saecke van welcke quaden uijtslagh sijne gantsche ruine dependeerde, sulcx door het aenraden van den voorsz. heer Samuel Nassy is hij door haer versoght geweest uyt haere naeme en van harentwegen haere bekentenisse ende confessie te comen doen van seven en twintigh stucx slaaven soo groot als kleyn voor haere reeckeninge te hebben overgebracht om die ter sluyck tot haer proffijte hier te vernegocieren boven en behalve eene om op het versoek van den commies off assistent $\mathrm{m}^{\mathrm{r}}$ Coderc, in Angola woonachtigh, alhier aen sijn broeder Coderc te willen behandigen, het welcke alsoo oock is geschiet.

Dese trouwlose minedigheyt heeft mijn doen geloven dat, dat nestje werdende geroert, nogh wel eyeren soude werden gevonden om struyff te backen het welcke mijn heeft bewogen om den capiteyn hier aen landt te houden, het schip door soldaten in besettinge te nemen ende nevens ofte geaccompagneert van de heer fiscael, mijne secretaris als verscheyde andere officieren met de twee schippers van onse barcques aen 't boort te vaeren, alwaer alle tot bekentenisse hebbe gebracht, dogh den supercarga seght, geene de minste part ofte deel in de voorsz. gelorrendrayde slaven te hebben gehadt, het welcke door den capiteijn en andere scheeps officieren is geconfirmeert geworden, maer door mijn ondervraeght sijnde ofte van haere handel geene kennisse en hadde gehadt, heeft geseght van het geheel getal niet, maer wel van tien off twaelff; Vrijdagh ontrent negen uyren smorgens is de bekentenisse geschiedt; ten twee uyren 's naemiddaghs ben ick aen 't boort gevaeren ende is die achtermiddagh nevens den geheelen dagh van gisteren geamployeert om het schip te visiteren, hier nevens gaet een kleyn lijstie tot dato deses uyt gevonden; het schip van Note sijnde in zee gesteecken is waghtende op dese mijne brieff, sulcx per naeste breeder onderreght van alles sal cunnen doen, sijnde mijn oock onmogelijck bij dese gelegentheijt de copyen van de voorgaende depeches hier bij te connen voegen, het welcke tot de naeste gelegentheyt sal werden gediffereert. Den 
capiteyn, nevens de officieren van het voorsz. schip de Vrede hebben van het beginne mijn gerepresenteert, dat het voorsz. schip niet in staate en was, om van dese winter te reverteren alsoo seer leck was binnen gecomen ende hier genootsaeckt soude sijn te kielhalen, het welcke seer quade effecten doet tot de inladinge, versoeckende dierhalven in het toecomende van betere scheepen te mogen werden versorght. De slaven hebben tot eene seer hoge, jae tot eene al te hoge prijs vercoght geweest; sal mijn debvoirs doen, dat het schip het beste doenlijck ras ende wel versorght werde, om voor nieuwe jaer te connen vertrecken. Op dese Coert hebbe in den vollen raet lecture gedaen van den geheelen missive door mijn aen UEd. Gro, Achtb. geschreven van den 23 e Augustij laestleden met versoeck offer iemant was die iets in het minste hier tegens kennisse hadden, dat hetselvige gelieffde bekent te maecken, dogh hebben alle geacquiesceert ende verclaert daertegens niet te hebben. Hebbe de selvige lectuyre aen schipper Note gedaen, in presentie van den Suyckerboer sonder iets hem concernerende te dissimuleren ofte verswijgen, sulcx Haere Ed. Gr. Achtb. op sijn aencomste oock gelieven te doen als oock aen de heer Commandeur Laurens Verboom; om kortheydt des tijts niet connende daer bijvoegen sal verblijven in alle trouw en oprechtigheyt.

\author{
Edele Groot Achtbare Heeren \\ UEd. Groot Achtbare onderdanigen dienaer \\ Actum Suriname \\ C. van Aerssen van Sommelsdijck \\ den $\mathrm{X}^{\mathrm{e}}$ September 1684. \\ Sedert de blanc seings
}

Uyt Zuriname den 23e September 1684.

\title{
Edele Groot Achtbare Heeren
}

Wil verhopen dat mijne laesten, aen UEd. Gro. Achtb. geschreven van dato den XI September, door schipper Note UE. wel sal sijn geworden, bij welcke occasie ick haere Ed. Gro. Achtb. hebbe bekent gemaeckt de lorrendrayerije door den capiteyn Petz nevens alle andere officieren van het schip de Vrede, als mede de supercarga daervan niet exempt sijnde ten reguarde van hetselvige te hebben gedooght, geconcenteert ende geconniveert soo uyt insighte van sijne particuliere gedrevene negotie ofte andere interesse bij hem bedongen, waervan ick het naeder ondersoeck 
aen de heeren in 't patria sal laeten doen, matterie ende blijck uyt haere eygene confessie genoegh en demeerder hebbende als wert vereyst om minedige ende trouwlose te sijn ende werden verclaert, als mede vervallen in de peene ende boete daertoe staende, als haere Ed. Gro. Achtb. sullen sien uyt de stucken, door de heer fiscael als mede van den secretaris Broen bij dese occasie ende gelegentheyt toegesonden, aen dewelcke ick mijn sal referere om cortheyts wil, sullende daerbij voegen eene kleyne protestatie door mijn gedaen aen den commies Bruyser, als gemachtighde ende geauthoriseerde van de heeren Bewinthebberen van de Ed. Geoctroyeerde Westindische Compagnie, wegens de onbequaemheyt van het voorsz. schip de Vrede, hebbende van mijn debvoir geacht, sulcx te moeten en behooren te doen om presente als toecomende schade voor te comen, sulcke costelyke equipages bij gebreck van voorsorge hier niet connende blijven leggen, dat tot merckelijcke schaede ende praejuditie van de Societeyt, soo sulcx wierde ingewillight ofte gedooght, het schip buytendien seer onbequaem sijnde tot die handel, te cort sijnde ende mistimmert tot inschepinge van de reverterende inladinge van suyckeren, waerop versoecke de heeren altijt gelieven reflectie te nemen, dat het ruym magh werden bequaem gevonden, om vier hoogh te connen stuwen; Ick ben oock van gedaghten het voorsz. schip de Vrede, als sal sijn in staet gebroght van te reverteren, hetselvige geensints aen de conduiten van den capiteyn Pets en desselfs stuerman te vertrouwen maer met een eerlijck bequaem schipper, ende stierman te versien, sullende oock sorge dragen van met elck reverterende schip, eenige uytwisselinge te doen van officieren en mattrosen, om alle de samenrottinge, consequentelijck eenige disperate ende feytelijcke onderneminge voor te commen, als van luyden die geruyneert sijn van eere, reputatie als middelen, ende met soo een middel haere verlorene schade soecken in te haelen sijnde in deze gewesten plaetsen genoegh, alwaer soodanige guyten souden wilcom wesen. Nu met dese droge tijt bennen wij wederom besigh om een Coert met de Indianen te maecken om ten oorlogh te gaen binnen drie weecken, hopende dat ondertusschen Tobias Adriaense ofte eenige andere hier sullen sijn aengecomen, met eenige provisie, waervan ick voor onse militie soude hebben seer groot gebreck geleden, indien ick mijn niet en hadde beholpen door goede vrienden.

Hiernevens gaet oock copye van de brieven van de heer Command $^{\mathrm{r}}$ Boursse tot Barbise, als mede van den commandeur Beeckman tot Isekebe; den schipper rapporteert mijn mondelingh 
hier te sijn gecomen om eenigh volck ende slaven, tot dertigh ofte meerder in getal, hetwelcke ick niet en hebbe willen inwiggelen als daertoe door de heeren Bewinthebberen sijne meesters niet sijnde versoght, ende ick wel achterdoght hebbe gekregen ofte het wel moghte sijn tot particuliere handelinge ende negotie, als alleen dienende tot advyis van de heeren Bewinthebberen, gaet oock hier nevens antwoort op deselvige brieven.

Wenste wel met den eersten te mogen werden versorght van drie bequame, ende naerstige scheepstimmerluyden tot onderhout ende reparatie van onse vaertuygen alhier, sijnde ten hoogste nodigh daeraen geduyrigh de handt te houden, doordien alles hier soo vergaet door de cracht van de lught ende de wormen, en versoecke dat mogen wesen verbonden voor den tijt van drie jaeren, anders werden stracx gedeboucheert door andere particulieren, doordien hier veel meerder cunnen winnen, ende elck vaertuygh wel diende versien te wesen met eenen timmerman, hebbende tot noghtoe ons moeten behelpen met het affbedelen van de gaende ende comende scheepen haere timmerluyden, die se selfs qualijck connen missen. Ende alsoo ick bevinde, dat door de wintmoolens seer bequaem alhier sal connen suycker gemaelen worden, als door de banck alhier een doorgaende couwe waeyt, wenste wel dat met het aldereerste, ende soo haest doenlijck hier drie a vier meester molewerckers wierde gesonden, elck versien met drie a vier kneghts, het welcke soude strecken tot merckelijke beneficie ende voordeel van de colonie, jae tot soulagement van ten naesten bij van de helft van de costen, die de planters gehouden sijn te doen, soo tot den incoop van de beesten als het jaerlijcx versterff, dat soo groot is, dat niet genoeghsaem connen werden versien, als reets voor dese hebbe geschreven ende sedert door eene extraordinare sterffte sooseer vermindert, dat de gantsche reviere van Suriname ten naesten bij stille staet, tot merckelijcke nadeel van de colonie ende planters, sulcx het beste ende prompste remedie is waerdoor connen werden geholpen; dogh dat wert acht genomen, dat geene dronckaers hier werden versonden, soude voor goede ende bequame meesters geern concentere twee hondert ducatons, jae tot seven hondert gulden in 't jaer ende cost, oock eenige steenbackers en pottenbackers, als bij meest alle mijne voorgaende hebbe kenisse gegeven, sijnde onmogelijck sonder timmerluyden van alle soorte deze colonie voort te setten naer behooren, ende die in Brabant als ick onderright worde overvloedigh sijn te becomen; het recruteringh van soldaten hier bijvoegende, sal ick verblijven naer presentatie van 
mijnen onderdanigen dienst, hebbende haer Ed. Gro. Achtb. verseeckert, dat alles hier Godt sij gelooft ende gedanckt dese colonie naer wens voortganck neemt, waermede eyndigende verblijve

\section{Edele Groot Achtbare Heeren \\ UEd. Gro. Achtb .onderdanigen dienaer \\ C. van Aerssen van Sommelsdijck \\ Sedert de blanc seings.}

Ende off haere Ed. Gro. Achtb. iemant weten uyt te vinden die dit gouvernement beeter naer haere intentie weet waer te nemen ende te gouverneren, sal met vreughde sijne overcomste tegemoet sien ende hetselvige hem overdragen, niet als gerebuteert sijnde, maar bevindende de inwoonders deser Colonie volgens de vaderlantsche onderrightinge onwaerdigh dat voor haer moyte ende costen worden genomen, dogh hier passeert niet minder dan hetgene daervan ben onderreght uyt het vaderlandt, sijnde alles seer soepel ende gedweegh, sulcx wel soude vertrouwen het uyt $\mathrm{M}^{\mathrm{r}}$ Scherpenhuyses coocker comt, die niet wel gecontenteert is, dat niet tot Gouverneur is aengestelt geweest, hebbende uyt dat insighte hem niet willen laeten gebruycken tot Raet, sijne excusen op andere frivole redenen nemende, gelieven het de Heeren eens met hem te proberen sal met playsier soo eene wijse directie beogen en ettelijcke tijt bijwoonen, de vrienden die hij hier heeft sijn verseecker seer weynigh en hoe reghtvaerdigh hij hier in de regeringe heeft voor de interesse van de colonie volgens sijne eedt ende plicht geviguleert, sal het boeck van den ontvanger-generael Wilbort Daniels getuigenisse geven, alwaer blijckt, dat nooyt meer dan vierhonderd ackers heeft aengegeven ende vierduysent ofte bij coop ofte warringh besit, hetselvige hebbende mede gedaen wegens hooftgelt naer proportie, als mede geene uytgaende ende incomende gereghtigheyt betaelt, en daer en boven wijl nogh gesegent van een tractament van twaelff hondert gulden's jaers als Raedt, sonder concent van den Staet van Zeelandt, sulcke regeerders en sulcke regeringe souden sij begeren daer elck een sigh segende; soo de Heeren daermede gedient sijn sal die hier wel sijn te becomen.

Hiernevens gaet het Octroy, gelieven hetselvige met opmerckinge naer te sien en op de aenteyckeninge reflectie te nemen, versoecke met het eerste schip een dosijn of twee van deselvige exemplaren van het octroy, dit sijnde het leste dat ick overigh hebbe, alsmede dat ick wil verhopen dat haere Ed. Gro. Achtb. 
van haer gereghtigheyt duydelijck in het octroy geexpresseert niet en sullen gelieven aff te staen, hetwelcke verhope haest te sullen verstaen tot antwoort van mijne voorgaende nevens het oversenden van het placaet dieswegen geêmaneert ende alles duydelijck ende claer geexpresseert.

$$
\begin{aligned}
& \text { C. van Aerssen van Sommelsdijck } \\
& \text { sedert de blanc seings. }
\end{aligned}
$$

Edele Groot Achtbare Heeren,

Sedert mijnen laesten van den 23e September per het schip de Coninck Davidt, sijn hier wel ende geluckigh gearriveert de scheepen Jan ende Marya, schipper Walingh Janse Keyser van Rotterdam op de $25^{\mathrm{e}}$ September, sijne aen mijn geaddresseerde despeches hebbende achter uyt geseylt ende aen landt gelaeten; heeft mede gebracht twee smidts, een coperslager en twee soldaten voor reeckeningh van de Ed. Societeyt, dogh en wert onder de overgesondene annotatien niet gevonden wat ende hoeveel deselve op de handt, ofte tot Amsterdam genote hebben het welcke met de eerste gelegentheyt sullen te gemoet sien, als mede het schip de Johanna schipper Cornelis Antheunisse van Vlissingen op den 13e October; het schip het Slodt te Muyden capiteyn Tobias Adriaense, van Amsterdam op den $20^{\circ}$ October; het schip Sommelsdijck schipper Sijmon Jacobse Jongh van Amsterdam op den $15^{\mathrm{e}}$ November; met capiteyn Tobias Adriaense hebben wij alle de magasijns-behoefften, alsmede alle hem aenbevolen goederen volgens de cognossementen wel geconditioneert ontfangen, het welcke mijn uijt groote becommeringe ende van een seer swaer hooft heeft verlost, want ons laeste rantsoen was uytgedeelt ende hier geene gelegentheyt en is om iets te becomen, voornamentlijck van erten en grutte, bij gebreck van levensmiddelen alhier door de hooge waaters verdroncken, moetende meest de slaaven daermede worden onderhouden ende gespijsight, hopende dat sulcx niet lange meer en sal duyren, als sijnde te costelijck, oock werter sterck ingevrocht om daerinne te versien. Het geene waermede haer Ed. mijn hebben gelieven gedaghtigh te wesen is mijn van herten aengenaem geweest, dogh die groote quantiteyt te gelijck veroorsaekt schaade ende ongelegentheijt wegens het opeeten van de wormen, die de vaaten soodanigh door booren dat ongeloofflijck scheynt, dat een oxhooft in een naght geheel uytloopt, het selvige werden wij nogh eerder gewaer aen den asijn, die ons hier oock van weynige dienst is, hebbende hier de oranges ende 
sitroenen overvloedigh, waermede men sigh genoegh can behelpen ten waere een oxhooft ofte twee in het jaer ten hooghsten, sulcx soude in het toecomende mijn versoeck sijn het selve te verdeelen in drie a vier perceelen, een helft witte ende d'andere helft roode vyn de Grave, die hier wel de gesontste is ende het water wel verdragen can.

Met het schip de St Jan sijn reets de gefourneerde reeckeninge van de militie overgesonden alsmede de staet van haere behoefften can werden gesien, twijffele niet ofte sullen hebben contentement gegeven, doende alle vlijdt ende naerstigheyt, van alles met de uytterste trouw ende correctheyt naer te comen ende doen observeren, elckeen in sijne officie exactelijck observerende het welcke men hier soo niet gewent en is gelijck claerlijck blijckt uyt de boecken van de voorgaende jaeren van den ontfanger, hetwelcke gotloos is te sien ofte te hooren en de grootste landtsdieven waeren de gouverneurs, commandeurs, nevens den Ed. Raedt en als dan was de provintie van Zeelandt wel bewaert;wat den ontfanger Wilbort Daniels reeckeninge concerneert, met alle voorvoorvallende veranderinge geeft ons dagelijcx soo groote moeylijckheyt dat niet voor het laeste van dit jaer sullen connen claer vallen, want met de uyt en incomende scheepen alwat vrij te doen valdt, omde oude coruptie te doen affsterven. Rudolph Kith hier in dienst als soldaet sijnde hebbe hem sijn affscheyt op UEd. ordre toegestaen, heeft dogh eghter dese uyttocht willen doen voor en al eer hij wilde repatrieren.

Nicolaes le Bré hier hebbende altijt sijn tractement genoten, sijnde sijn maentgelt brieffje vermist geweest werden UEd.: versoght niet meer te laten volgen aen sijn wijff ofte aen iemandt anders op het voorsz.brieffje want hij hierdoor veel ten achteren geraeckt is, waer op sal staet maecken.

Wij sullen oock de steenbackers als ten hooghsten nootsaeckelijck, nevens de molemaeckers soo waater als andere, als voor sluyswercken bequame timmerluyden bij gelegene occasie affwaghten, bedanckende haer Ed. wegens de geene die met het schip Sommelsdijck nu hebben ontfangen, dogh hebbe verstaen, dat twee van de selve haer Ed. hebben bedrogen haer voor timmerluyden uijtgevende, sijnde door de ziel-vercoopers daertoe aengeraden geworden om meerder gelt te bedingen als grooter maentbrieffjes tot haer proffyt te maecken.

De occupatie van de Coert die hier heeft begost den $6^{\mathrm{e}}$ deser maent, die de geheele weeck geduert heeft, waerop is gevolght inmediatelijck den uyttoght van meest onse Christenen militie 
nevens Indiaensche vrienden, die den $17^{e}$ sijn vertrocken ten oorloge, gecommandeert door capiteyn Paeu, hebbende mijn soo veele occupatien gegeven dat ick gaerne bekenne seer vermoeyd ende gefattigeert niet van lichame soo veel, maer tot in de ziele te sijn, want ick de dingen zelfs maniere, ende op andere $n$ iet en laet aencomen: sulcx haere Ed. mijn sullen gelieven te excuseeren, soo ick mijn niet meerder en extendere, hetwelcke in voorvallende occasie gevoeghlijcker sal connen doen, als beter daer toe als-dan sullende sijn gedisponeert, dogh mijn invallende het geene haere Ed. Gro. Achtb. gelieven te weeten wegens de verdeelinge die geschiet is in de slaaven hebbe niet beeter geweeten ofte hadde daervan kenisse gegeven, sijnde die in drieen verdeelt ende geloodt in presentie van den Raedt en de gantsche gemeente, om alle ongereghtighheyt ende quade opspraeck te vermeyden; mijn gedeelte hebbe ick naer mijn genomen tot voortsettinge van plantages, op dewelcke sij oock bij lootinge sijn verdeelt geworden, ende de resterende die weynigh sijn geweest, aen de een offde andere overgedaen ende vercoght, hebbende eerst gezien wat mijn het beste diende, ben verseeckert dat dat de heeren in de vercoopinge niet en heeft te cort gedaen nogh in het verdeelen van de slaaven op de plantages; soo de heeren hier iets tegen hebben, gelieve te laeten weeten, sullen seer light werden gecontenteert en ick als dan oock beeter mijn intrest bij vinden sall:

Godt sij gelooft ende gedanckt, alles is in een gewensten staet alhier naer de tijt ende avancere dagelijcx in ruste ende vreetsaemheyt gelijck UEd. Gro. Achtb. uyt mijne vorige sult hebben verstaen, wenste het in ons vaderlandt soo moghte werden bevonden; de quaade gerughten die van mijn in dit landt hebben geloopen raecken aen mijne oude kleeren niet, ick weet op wie ick steune ende vertrouwe, die en can met geene illusies gepreoccupeert ofte bedrogen worden. Ick hebbe het wel geweeten, ende geseyt, dat het soo gaen soude, admitteert eerelijcke ongepassioneerde ende gedisinteresseerde luyden om getuygenisse der waerheijt, en niet soodanige die haere uytterste debvoiren doen om de luyden te persuarderen dat ongeraden is eenige forteresse ofte sterckte op te slaen hier te lande tot affweeringe van de Europiaensche vyanden, als niet bestandigh connende wesen om die te connen resisteren ende hetselvige haere ruine is en van haere plantages, met haer te willen verweeren ende diffenderen daer ter contrarye sij altijt seer minnelijck sullen werden getracteert als haer goet-willigh sonder denfentie sullen 
comen over te geven; hebbende oock gepretendeert dat den gouverneur alhier geen militaire behoorde te wesen om tot die caracter te mogen aspireren ende sijn onbequaemheyt niet doen blijcken, hovaerdighheyt ende onbequaemheyt bennen altijt vergeseltschapt voornamentlijck bij luyden die niet gehadt en hebben ende tot iets geraeckt sijn, ende dan bennen comen kijcken in de weerelt als door een gaetje van de deur; het excuseren van tot Raet geeligeert te werden is op die moer gebrouwen geweest, en heeft sijn oorspronck uyt de suerdesem van hovaerdighheyt waermede hij hier weynigh eere heeft ingeleght ende hem seer odieux gemaeckt onder den Raedt ende de gemeynte; Hier wert seer gedoleert onder de voorsz. colonie over de exorbitantie van het reeckenen der tarra tegens hondert en dertigh pondt suycker het oxhooft, seggende rontuyt, dat sij aen Amsterdam niet en sijn gebonden en soo men daerinne niet en wil voorsien, dat sij op Rotterdam en op Zeelandt sullen inscheepen, alwaer haer die op hondert ponden wierden aengereeckent, ende nu hier een order ende regel gestelt is op de tarra, dat die gebrant wert op de vaten, mijns oordeels soude cunnen werden vast gestelt dat een vadt dat sestigh pondt heeft geteeckent voor het intrecken van de suykeren op een vast getal sal werden gestelt, van gelijcken een vadt van 70 , een van 80 , een van 90 van gelijcke, en voorts naer proportie waerop de heeren van de Societeyt gelieven communicatieff met de heeren Burgemeesteren te gaen tot het beste van de stadt, want ick bemercke dat Zeelandt en Rotterdam daer op toeleggen, ende hier eenige sijn die dat lijntie beginnen te trecken, waerinne mijns oordeels van den beginne wel diende te werden versien, niet soudende redelijck wesen dat wij alle de moeyten soude doen ende de costen ende een ander de beste vrughten van genieten. De saecke van de stieurman nevens eenige mattrosen van het schip de $\mathrm{St}$ Jan capiteyn Schepmoes is costeloos ontslagen sulcx sijne verschene gages los sijn.

De Zeeuwsche scheepen continueren nogh met hout- en soutbrieven te vaeren, van dewelcke ick de laeste hebbe gescheurt, den capiteyn ofte schipper gerestitueert, hem verseeckerende dat hij met hetselve niet en conde volstaen, en soo hij niet en sorghde, dat voor sijn vertreck van hier uyt het vaderlandt van beeter wierde versien, hij hier aen mijn genootsaeckt soude sijn te betalen; gelieven oock de heeren goede sorge te dragen dat de scheepen aldaer equitabel werden gemeten;

Het vercoopen van de slaaven op termeynen als sijn vercoght, hebben de heeren geen redene van haer te beclagen, oock was 
niet mogelijck haere scheepen binnen de negen off tien maenden hier te laeten leggen te connen expedieren, dogh de heeren hebben het proffyt ende ick het verweyt; Sed transeat cum ceteris erroribus; oock sijn de heeren seer geabuseert van te geloven dat sulcx soude hebben occasie geweest van dat de kleyne planters aen geen slaaven hebben cunnen geraecken,daer ter contrary alle generalijck om niet te seggen het meeste deel aan de kleyne planters sijn vercoght geworden, sulcx dat de heeren sullen cunnen sien, dat geen tien planters uijt dese twee scheepen slaaven hebben genoten, ende dat door een middel, dat al evenwel corect sijn betaelt geworden; en met de heere haere permissie ende goetvinden, soo sal ick tot het gemeene best voor de laeste reyse bedingen een oxhooft suycker contant ofte binnen twee maenden te betaelen ende in het toecomende alle termeynen van ses tot ses maenden, volgens het geene bij mijn van den beginnen is beslooten te observeren, waermede ick als dan alle incomende negerscheepen can depecheren, hetwelcke aen UEd. Gro. Achtb. en aen de gemeynte alhier moet goet doen, connende hetgeene UEd. Gro. Achtb. aen het retoer van het schip mesnageert hier de slaaven soo veel te beter coop geven; dat haer Ed. hier selfs waeren soude verzeecker van veele saecken heel anders oordeelen, den tijts al het oock leeren, hoope selfs voor den ontfangh deses sullen hebben cunnen mercken, maer Godt danck ick en ben voor geen kleyn gerughtje vervaert en voor het gemeene beste durff ick wel wat op mijn hoorns nemen; en ick en pieque me niet van eene timide politie te wesen, maer wel van equiteyt ende justitie, en sigh naer de tijden, ende plaetsen wat te reguleren; seecker hadde ick de dingen niet gedaen uyt een principij van eer en met vreughden, ick souden mijn niet hebben cunnen deur redden, want ick liever twintigh colonien soude willen ondernemen op te righten, dan soo eene vervallene, ende gecorrumpeerde te herstellen, Godt sij gelooft ende gedanckt dat soo verre gebraght is; en voor Godt verclaere ick om hondert duysent rijcxdaelders ick diergelijcke werck onseecker van de uytcomste, niet soude willen beginnen ende ondernemen. De heeren cunnen dit spelenvaeren noemen, ick gunne haer die vreught, en sij sullen mijn van harte welcom wesen, den aerbeyt en verveelt mijn niet, en ick ben, Godt sij gelooft ende gedanckt, in volcomen gesontheyt en soo lange die continueren sal sal het wel gaen met Godt. Met de commies Tibaud alles hebbende overleght, hebbe hem geordonneert articulatum van alles UEd: Gro: Achtb: te informeren waeraen mijn ben refererende om cortheytswille. 
Haere Ed: Gro: Achtb. gelieven noghmaels te doen divulgeren, dat hier sooveel scheepen niet over en comen, want onmogelijck sulle sij haere ladinge binnen een jaer cunnen becomen, uyt oorsaecke van de groote schaede, die de hoge waaters hier hebben gedaen, waerdoor seer veel riets is verdroncken ende seer veel paerden ende beesten sijn gestorven, sulcx seer veel moolens verlegen sijn ende genootsaeckt sijn van drie meulens maer eene te doen gaen; Ick vrage haere Ed: Gro: Achtb. in dit geval soo het geviel, dat ick nu uyt Turkijen ofte elders paerden ofte beesten coste becomen, wat soude de heeren mijn raden te doen, Godt geve dat soodanige occasie sigh presentere, ende sij sullen hooren ofte ick sal doen volgens den raet die sij mijn soude hebben gegeven, soo ick soodoende niet wel can doen dat is mijn ongeluck, ick hebbe niet beeter geleert, oock soude ick van andere in gelijcke gelegentheyt niet anders vergen; haere Ed: Gro: Achtb: sijn nu van mijne meenige, ende gedaghten geinformeert; soo se mijn de eere gelieve te doen van mijn de haere te laeten toecomen, ofte ick sal mijn daernae conformeren ofte haere Ed: Gro: Achtb: bedancken. Hier bijgevoeght hebbende de copye van mijnen laesten aen UEd: Gro: Achtb: den 23 September geschreven sal ick naer hertelijcke toewensinge van Godes H. zegen ende protextie verblijven

\section{Edele Groot Achtbare Heeren}

UEd. groot achtbare onderdanigen dienaar C. van Aerssen van Sommelsdijck Sedert de blanc seings.

Actum Paramaribo in

Zuriname op den $20^{\mathrm{e}}$ November 1684

De twee Grevebroecken zijn beyde met Tangen vertrokecn sijnde hier met de oude soldaten gelicentieert geweest, hebbende oversulcx H. E. G. A. haere voorschrijvens niet van doen gehadt en bij alle occasien sullen maer gelieven te commanderen. 